\title{
Effects of water deficit on the growth and yield formation of maize (Zea mays L.)
}

\author{
Salifu Mahama \\ University of Debrecen Kerpely Kálmán Doctorial School, Debrecen \\ salifu_mahama@yahoo.com
}

SUMMARY

\begin{abstract}
Maize (Zea mays L.) is the most important consuming cereal crop in the world after rice and wheat. This requires an understanding of various management practices as well as conditions that affect maize crop performance. Water deficit stress during crop production is one of the most serious threats to crop production in most parts of the world and drought stress or water deficit is an inevitable and recurring feature of global agriculture and it is against this background that field study of crops response to water deficit is very important to crop producer and researchers to maximize yield and improve crop production in this era of unpredicted climatic changes the world over.

A pot experiment was carried out to determine the effects of water deficit on growth and yield formation of maize. Two maize cultivars were used Xundan20 and Zhongdan5485. Three levels of soil water content were used in two stages of water control levels at two stages of the maize plant development

1. The JOINTING STAGE: A. CONTROL (CK) soil water content: from $70 \%$ to $80 \%$ of soil water holding capacity at the field, soil water content: from $55 \%$ to $65 \%$ of soil water holding capacity at the field, soil water content: from $40 \%$ to $50 \%$ of the Soil water holding capacity at the field.

2. The BIG FLARE PERIOD: A. CONTROL (CK) soil water content: from $75 \%$ to $85 \%$ of soil water holding capacity at the field, soil water content: from $58 \%$ to $68 \%$ of soil water holding capacity at the field, soil water content: from $45 \%$ to $55 \%$ of the soil water holding capacity at the field.

This research mainly studied the effects of water deficit on physiological, morphology and the agronomical characteristics of the maize plant at the different water stress levels.

The importance of these results in this experiment will enable plant producers to focus and have a fair idea as to which stage of the maize plant's development that much attention must be given to in terms of water supply.
\end{abstract}

Keywords: maize, water deficit, vegetative, production, reproduction

\section{INTRODUCTION}

Maize (Zea mays L.) is a major cereal crop world over, serving as a major staple for both human consumption and animal feed. Maize constitutes a stable food in many regions of the world. It is a basic stable for large population groups particularly in developing countries (FAO 2008). Maize can be eaten in many form forms in many parts of the world, it can be boiled or roasted on the cob, the grains can be cooked fresh or dry and the dry grain can be made into popcorn and eaten with roasted groundnuts (Doebley 1994).

The consumption of maize as feed has also increased tremendously with the development of poultry and livestock industry. Maize is one of the grain crops in the world which is the most versatile. It is used in the human diet in both fresh and processed forms. The value added has been an important economic driver in the corn markets (Hallauer and Miranda 1988).

It has also become a major resource for industrial applications and bioenergy production. Maize grain is widely used for the preparation of corn starch, corn syrup, corn oil dextrose, corn flakes, gluten, grain cake, lactic acid and acetone which are used by various industries such as textile, foundry, fermentation and food industries.

Drought is a protracted period of water deficient precipitation resulting in extensive crops damage and yield loss. Drought stress or water deficit is an inevitable and recurring feature of global agriculture. Kramer (1980) reported that about one-third of the world's potentially arable land suffers due to water shortage, and most of the crops production is often reduced by drought. Water being integral part of plants plays a pivotal role in the initiation of growth, and subsequent maintenance of developmental process throughout the plant's life. The maize crops may experience reductions of grain yields when subjected to water deficit during the critical period of crop cycle from tasseling stage to initiation of grain filling.

During 1998/1999 a long drought period, $48.8 \mathrm{~mm}$ rain only allowed grain yield of $4.8 \mathrm{t} \mathrm{ha}^{-1}$. While during the year 2002/2003 a short duration drought at critical period reduced grain yield less than $2 \mathrm{tha}^{-1}$, affecting the ear per plant and kernel per ear (Bergamaschi et al. 2004).

However, maize plants are also very susceptible to drought and heat; each year, an average of $15 \%$ to $20 \%$ of the potential world maize production is lost due to these stresses (Lobell et al. 2011). The total yield loss depends on when the stress occurs at the plant growth stages, as well as the duration and the severity of the stress. Early season drought reduces plant growth and inhibits plant development (Heiniger 2001). Climate change refers to any change in climate overtime, whether due to natural Variability or as a result of human activity (IPCC 2007). While climate change is a global phenomenon, the impact of climate change on maize production cannot be over emphasized as it bring a lot of undesirable conditions on maize plants such as drought, high heat waves, flooding etc. all of which in one way or the other has an impact on the growth and yield of maize which rural poor communities rely greatly for their survival as an agricultural product. 
Many studies regarding climate changes and their foreseen influence on agriculture and other domains of the economy have been published recently at international level. According to the report of the IPCC working group II, globally, an average temperature increase of 4.3 to $6.30{ }^{\circ} \mathrm{C}$ is expected until 2100 , as well as an increase of extreme meteorological phenomena (storms, heat waves, drought, floods), spatial and temporal differences being obvious both at global and regional levels (Parry et al. 2007).

Water deficit is one of the common environmental limitations to crop productivity, affecting growth through alterations in metabolism and gene expression (Leipner et al. 1999). Under drought stress, water uptake of the crop is insufficient to meet evaporation demand. Maize yields may be reduced by water deficit occurring at any stage, but largest effects are when drought coincides with the seedlings, flowering, and late grain filling stages of their growth. Given the above scenario, there are dare consequences and effects to agriculture and its practices among many farmers in world over. This is as witnessed in continuous crop failures and reduced yields in most agricultural products over the years. There is therefore the need for more research to be done on the impact of drought on maize production and at what stage, awareness creation and general education to farmers on issues of drought in recent time as a result climate change and its impact on agriculture.

Global demand for maize will increases as a result of the over increasing world population and its demand for food and it's usage as an industrial raw material for many product (Rosegrant et al. 1999), thus the need to increase world production of this economically variable crop. But the effect of drought or water stress is limiting the production of this maize plant as it is mostly grown under irrigated condition in most parts of the world due to shortage of rains, and thus limitation on water use is being imposed in every crop as a result of the scarcity of water (Araus et al. 2002).

Maize use moisture efficiently, requiring about $500-800 \mathrm{~mm}$ of water during its life cycle of 80 to 110 days (Critchley and Klaus 1999). According to Jamieson et al. (1995) water requirement of maize at the time of tasseling is $135 \mathrm{~mm}$ month $^{-1}\left(4.5 \mathrm{~mm}\right.$ day $\left.^{-1}\right)$ and this requirement may increase up to $195 \mathrm{~mm} \mathrm{month}^{-1}$ (6.5 $\left.\mathrm{mm} \mathrm{day}^{-1}\right)$ during hot windy conditions.

Crop production in any location in the world cannot be carry out meaningfully without enough water supply to the crops, but unfortunately, due to climate changes and its impact on the environment, most crops are grown in many parts of the world without enough water supply at some parts of the crops developmental stages. It is against this background that this research is carried out to look at the effects of water deficit on the vegetative and reproductive yield and yield components process of maize plant.

It is necessary to know such effects of water deficit at different stages of crop growth in order to develop crop management strategies to minimize the risk in maize production. Therefore, this study was conducted to determine the effects of water deficit at vegetative and reproductive stages on growth and productivity of maize.

\section{MATERIAL AND METHODS}

Plants responses to soil water deficits are often performed under greenhouse or controlled - environmental conditions. Such studies may be undertaken to characterize fundamental physiological responses of plants to drought stress, or to identify genetic variability for drought tolerance to be used in crop breeding programs.

The experiment was carried out in the experimental garden of the west campus of China Agriculture University on the no: 2 Yuanmingyuan west road Beijing, 100193 P R, China.

Two maize cultivars were used, with one cultivar Xundan20, more sensitive to water deficit, and the other, Zhongdan5485 tolerance to water deficit. The maize cultivars are the current and most widely used in China.

The maize seeds were planted on June 23, 2013 in plastic pot containers with $30 \mathrm{~cm}$ height and about $25 \mathrm{~cm}$ wide with 4 drainage holes at the bottom. The culture soil was one volume peat soil mixed with one volume vermiculite. The soil was completely dried. Each pot contained the same weight of soil of $4.0 \mathrm{~kg}$. In addition, each pot contained $50 \mathrm{~g}$ dried chicken manure and $7 \mathrm{~g}$ of compound fertilizer, $\mathrm{N}: \mathrm{P}: \mathrm{K}=15: 15: 15$. The soil was completely mixed with the chicken manure and compound fertilizer. Then the maximum water holding capacity was measured using Wilcox method (Wilcox 1959). (Mass of the water contained in the saturated soil/mass of the saturated soil $\times 100$.)

The experimental treatment of the varieties was arranged in a randomized complete block design with four replications. Evaluation was conducted on plot with size of $5 \mathrm{~m} \times 5.4 \mathrm{~m}=27 \mathrm{~m}^{2}$, which comprised eight rows of maize plants. Healthy seeds were sown by hand at approximately $3-4 \mathrm{~cm}$ depth and at a spacing of $30 \mathrm{~cm}$ between the plants and $60 \mathrm{~cm}$ between the rows.

Three levels of soil water content was used in two stages, with each stage lasting for 10 days i.e. (i) control, from $70 \%$ to $80 \%$, (ii) from $55 \%$ to $65 \%$, (iii) from $40 \%$ to $50 \%$. During the period, the water loss from each pot, i.e. the amount of watering was determined gravimetrically daily at 7 o'clock. Then the soil water content of all pots was kept from $70 \%$ to $80 \%$.

The second water control experiment began at vegetative stage 12 . Three levels of soil water content were used, i.e. (i) $75 \%$ to $85 \%$, (ii) from $58 \%$ to $68 \%$, (iii) from $45 \%$ to $55 \%$.

Each treatment had 4 replicates. Each replication required three pots, but four pots were prepared so that the most uniform three plants could be selected. For two cultivars, totally 130 pots was used and arranged in $27 \mathrm{~m}^{2}$ in the greenhouse.

Measurements on the photosynthetic rate were taken on the first leaf above the topmost ear that was usually exposed to sun-light in the field. Sunny days were selected for taking the measurements since cloudy weather could have an influential effect on the photosynthetic photon flux density on the leaf carbon exchange rate (Earl and Tollenaar 1998).

The chlorophyll fluorescence $(\mathrm{Fv} / \mathrm{Fm})$ is the ratio of variable to maximum chlorophyll fluorescence of dark adapted leaves provides a means for quantifying the maximum quantum efficiency. The chlorophyll fluorescence was measure using a Photosynthesis Yield 
Analyzer Mini-PAM (Heinz Walz GmbH, Effeltrich, Germany). The measuring light modulation frequency was set at $20 \mathrm{kHz}$ for field conditions.

Leaf Area was measured by taken the length of the leaf and the maximum width of the leaf and multiply by 0.75 as suggested by (Stickler et al. 1961)

\section{RESULTS AND DISCUSSION - EFFECTS OF WATER DEFICIT ONTHE GROWTHOF INTERNODE AT JOINTING STAGE (PLANT HEIGHT, STEM DIAMETER, LENGTH OF INTERNODES)}

\section{Plant height}

The effect of different water treatment has a significant effect on the height performance of maize in this research. There was a significant difference between the CK and XI1 and XI2 at the first water control level at both 55$65 \%$ and $40-50 \%$ respectively at $(p<0.05)$. There was also a significant difference between the first and second percentage levels. The reduction in plant height as a result of limited water supply is a common consistent reaction to water stress situation in maize production (Table 1).

In respect of Zhongda5485, which is tolerant to water stress, there was a significant difference between the CK and both ZI1 and ZI2 at the first level of water control level but there was no significant difference between the ZI1 and ZI2 at that level at $(\mathrm{p}<0.05)$ (Table 1).

Table 1

Effects of water deficit on the plant height and stem diameter at jointing stage

\begin{tabular}{cccc}
\hline Variety & $\begin{array}{c}\text { Treatment } \\
\text { (water content) }\end{array}$ & $\begin{array}{c}\text { Plant } \\
\text { Height } \\
(\mathrm{cm})\end{array}$ & $\begin{array}{c}\text { Stem } \\
\text { Diameter } \\
(\mathrm{cm})\end{array}$ \\
\hline \multirow{3}{*}{ XUNDAN20 } & $70 \% \sim 80 \%(\mathrm{CK})$ & $151.9 \mathrm{a}$ & $22.7 \mathrm{a}$ \\
& $55 \% \sim 65 \%(\mathrm{XI} 1)$ & $138.2 \mathrm{~b}$ & $16.6 \mathrm{~b}$ \\
& $40 \% \sim 50 \%(\mathrm{XI})$ & $126.3 \mathrm{c}$ & $15.2 \mathrm{c}$ \\
\hline \multirow{2}{*}{ ZHONGDAN5485 } & $70 \% \sim 80 \%(\mathrm{CK})$ & $168.8 \mathrm{a}$ & $18.7 \mathrm{a}$ \\
& $55 \% \sim 65 \%(\mathrm{ZI} 1)$ & $143.7 \mathrm{~b}$ & $15.9 \mathrm{~b}$ \\
& $40 \% \sim 50 \%(\mathrm{ZI} 2)$ & $141.7 \mathrm{~b}$ & $14.8 \mathrm{~b}$ \\
\hline
\end{tabular}

Note: data marked with the same letter in the same columns is not significantly different at the significant level of 0.05 .

\section{Stem diameter}

In the first level of water control, there was a significant difference between the CK and both XI1 and XI2 at 55-65\% and 40-50\%. Again there was a significant difference between the percentage levels in between XI1 and XI2 in Xundan20 variety where XI1 was significantly different from XI2 in the first stage. Results shown in Table 1.

In the first level of water control stage in Zhongdan5485, there was a significant difference between $\mathrm{CK}$ and both ZI1 and ZI2 at the first level, but there was no difference between the percentage levels although $55-65 \%$ saw a higher value of measurement as shown in Table 1.

\section{Lenght of internodes}

Measurement and analysis was done on the individual nodes of the two variety of the maize plant from the first node from the bottom of the plant to the eighth node on top of the plant. Below were the outcomes.
From the analysis of the first water control level at $55-65 \%$ and $40-50 \%(\mathrm{p}<0.05)$, there was no significant difference between CK and both XI1 and XI2 on the 1 . and 2 . nodes at both percentage levels of $55-65 \%$ and $40-50 \%$. At the 3 . and 4 . node, there was a significant difference between CK and both XI1 and XI 2 at 55-65\% and $40-50 \%$ respectively, but there was no significant difference between XI1 and XI2 at that level. At the 6 . and 7 . node, there was a significant difference between CK and both XI1 and XI2 at both percentage levels and also there was a significant difference between XI1 and XI2 at that level of water control. At the 8. nodes, there was no significant difference between CK and XI1,but there was however a significant difference between both CK and XI1 and XI2. At the first level of water control $\mathrm{p}<0.05$ (Figure 1).

Figure 1: Length of internodes of Xundan20

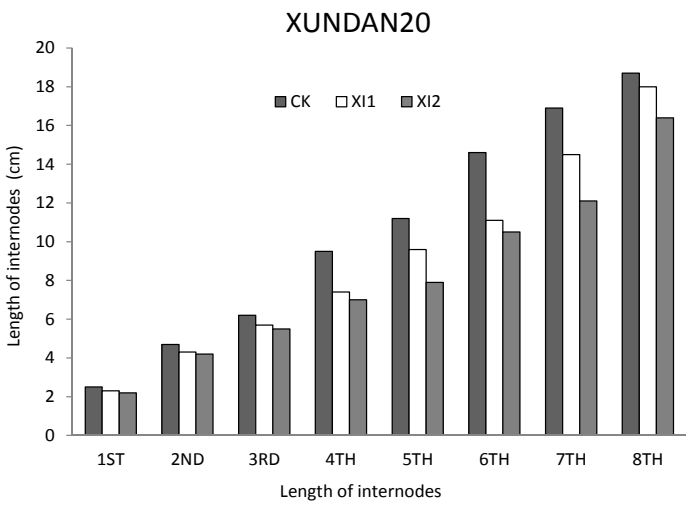

Measurements and analysis from the Zhongdan5485 variety shows that there were no significant difference between CK and both ZI1 and ZI2 in the first level at both percentage levels of $55-65 \%$ and $40-50 \%$ on the 1 . and 2. internodes. On the 3 . and 5. internodes, there was a significant difference between $\mathrm{CK}$ and both ZI1 and ZI2 at both percentage levels, but no difference was found between ZI1 and ZI2 at that level of water control. At the 4. and 6. internode, significant difference was notice between $\mathrm{CK}$ and both ZI1 and ZI2, and also there was significant difference between ZI1 and ZI2 at that percentage levels of water control stage. At the 7 . and 8. node, there was no difference between $\mathrm{CK}$ and both ZI1 and ZI2 at 55-65\% and $40-50 \%$ respectively at $(\mathrm{p}<0.05)$ this is shown in (Figure 2).

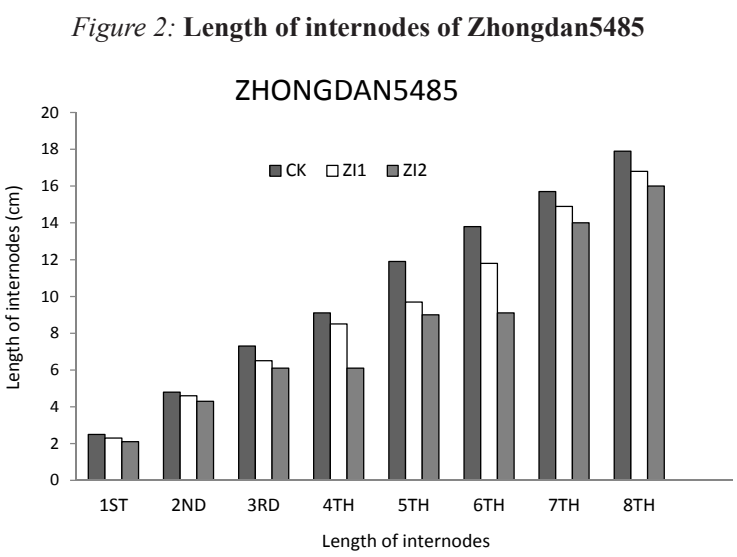




\section{Leaf Area}

The effect of water stress on leaf development or expansion cannot be over emphasized as this has been shown in this research in Table 2 at the first water control level where there was a highly significant difference between the control (CK) and both the XI1 and XI2 at both percentage levels of $55-65 \%$ and $40-$ $50 \%$ respectively in the Xundan 20 variety at $(\mathrm{p}<0.05)$.

In the case of Zhongdan5485 which is considered as a drought tolerant variety, there were evidence of the effect of water shortage at the vegetative stage (stem elongation stage) where there was a significant difference between the control (CK) and both ZI1 and ZI2 at the first water control level of $55-65 \%$ and $40-50 \%$ respectively $(\mathrm{p}<0.05)$. There was however no difference between the ZI1 and ZI2 (Table 2).

\section{Photosynthesis Rate}

From the analysis, the warning effect of drought on photosynthesis was very clear at the stem elongation stage of maize development. Comparing the control experimental unit (CK) with the reduced water limited crops at both percentage level of 55-65\% and $40-50 \%$, there is a significant difference at both levels $(\mathrm{p}<0.05)$.

There was however, no difference between the two levels thus XI1 and XI2 at the percentage level (Table 2).

With regards to the Zhongdan5485, there is no difference between the ZI1 and ZI2 at the first water control level of $55-65 \%$ and $40-50 \%$ respectively.
There was however, a significant difference between the CK and both ZI1 and ZI2 at that level of water control and this is shown in Table 2.

\section{Leaf chlorophyll}

There is no significant difference between the CK and the XI1 at the first stage of water control at the stem elongation stage of $55-65 \%(\mathrm{P}<0.05)$. But there is a significant difference between the $\mathrm{CK}$ and XI2 at the percentage level of $40-50 \%(p<0.05)$. This experiment shows that there is effect of water shortage on the maize plant at the stem elongation stage when there is a severe drought.

In the case of Zhongdan5485, there was no difference between the CK and both ZI1 and ZI2 in both percentage levels of $55-65 \%$ and $40-50 \%$ respectively at $(\mathrm{p}<0.05)$ results shown in Table 2.

\section{Effect of water deficit on chlorophyll fluorescence $(\mathrm{Fv} / \mathrm{Fm})$}

In the first water control stage in Xundan20, the effect of water stress was not much noticed between CK and XI1 but there was however significant difference between both CK and XI1 and XI2.

In the Zhongdan variety, no significant difference was notice between CK and both ZI1 and ZI2 at the percentage levels of $55-65 \%$ and $40-50 \%$ respectively (Table 2).

Table 1

Effects of water deficit on the photosynthetic parameters at jointing stage

\begin{tabular}{|c|c|c|c|c|c|}
\hline Variety & $\begin{array}{c}\text { Treatment } \\
\text { (water content) }\end{array}$ & $\begin{array}{l}\text { Leaf Area } \\
\left(\mathrm{cm}^{2}\right)\end{array}$ & $\begin{array}{c}\text { Photosynthesis } \\
\text { Rate }\end{array}$ & $\begin{array}{c}\text { Leaf } \\
\text { Chlorophyll }\end{array}$ & $\begin{array}{c}\text { Chlorophyll } \\
\text { Fluorescence } \\
\text { (Fv/Fm) }\end{array}$ \\
\hline \multirow{3}{*}{ XUNDAN20 } & $70 \% \sim 80 \%(\mathrm{CK})$ & $527.8 \mathrm{a}$ & $28.5 \mathrm{a}$ & $1.9 \mathrm{a}$ & $0.8 \mathrm{a}$ \\
\hline & $55 \% \sim 65 \%(\mathrm{XI} 1)$ & $428.8 b$ & $23.2 b$ & $1.8 \mathrm{a}$ & $0.7 \mathrm{a}$ \\
\hline & $40 \% \sim 50 \%(\mathrm{XI} 2)$ & $411.2 \mathrm{~b}$ & $22.1 \mathrm{~b}$ & $1.3 \mathrm{~b}$ & $0.6 \mathrm{~b}$ \\
\hline \multirow{3}{*}{ ZHONGDAN5485 } & $70 \% \sim 80 \%(\mathrm{CK})$ & $832.9 \mathrm{a}$ & $24.6 \mathrm{a}$ & $1.5 \mathrm{a}$ & $0.7 \mathrm{a}$ \\
\hline & $55 \% \sim 65 \%(\mathrm{ZI} 1)$ & $744.4 \mathrm{~b}$ & $20.3 b$ & $1.6 \mathrm{a}$ & $0.7 \mathrm{a}$ \\
\hline & $40 \% \sim 50 \%(\mathrm{ZI} 2)$ & $740.6 \mathrm{~b}$ & $19.6 b$ & $1.4 \mathrm{a}$ & $0.6 \mathrm{a}$ \\
\hline
\end{tabular}

Note: data marked with the same letter in the same columns is not significantly different at the significant level of 0.05 .

\section{DISCUSSION}

The effect of water deficit on maize production at various developmental stages of the crop and its effects on the yield components and formation cannot be over emphasized and it is evident in this research work.

From the analysis and comparison of crops whose water supply was withheld for some time shows a significant difference with the control experiment which has sufficient supply of water throughout the growing period. The warning effect of drought on photosynthesis was very clear at the stem elongation stage of maize development. The low level of photosynthesis rate on the maize plant could have an impact on food construction and also impact on the dry matter accumulation. Other researchers such as Kisman (2003) and Osborne et al. (2002) have also reported the effect of water limitation on photosynthesis and dry weight loss on maize. Water deficits at the first stage of water control level in this research shows a significant difference between the control experiment (CK) and XI1 and XI2 in the Xundan20 variety and also in the Zhongdan5458 variety at the stem elongation or jointing stage and this could cause pigment and plastid damage to the maize plant. There was also a significant difference between the control and the treatments at $40-50 \%$ level of stress for chlorophyll and chlorophyll fluorescence $(\mathrm{Fm} / \mathrm{Fv})$ at the first stage of water control level in the Xundan20 variety. Drought stress reduces chlorophyll and carotenoid as reported by Duysen and Freman (1975).

The effect of different water treatment has a significant effect on the height performance of maize in this research. There was a significant difference between the CK and the other low supplied water treatment plants in both varieties at the first water control level at both 55-65\% and $40-50 \%$ respectively at $(\mathrm{p}<0.05)$. The reduction in 
plant height as a result of limited water supply is a common consistent reaction to water stress situation in maize production. Water stress at vegetative stage significantly reduced the plant height as compared to well-watered treatment, whereas water stress at reproductive stage did not influence the plant height significantly as compared to well watered treatment. Nesmith and Ritchie (1992) reported a decline in the extension of stem and leaf, and a reduction of in intermodal length of corn in response to pre-anthesis water deficit. Sarwar and Ali (1999) studied the effect of water stress on two maize genotypes and reported a reduction in plant height in both genotypes. El-Neomani et al. (1990) also reported that at the beginning of rapid growth stress dramatically decrease maize height although dry matter production depends on the level of photo-assimilate during grain filling in the ear.

Leaf area per plant was significantly affected by water deficit as compared to the well watered plants in this experiment. Reduction in leaf area per plant as a result of water stress at the vegetative stage is due to decrease in turgor pressure which is important for cell enlargement. Many other researchers also reported a reduction in plant leaf area. Acevedo et al. (1971) reported that elongation of maize leaves was highly sensitive to slight reduction in soil and leaf water potential. Higher reduction of leaf area per plant due to water stress at reproductive stage might be due to accelerated leaf senescence at low leaf water potential. Aparicio-Tejo and Boyer (1983) also observed accelerated leaf drying in maize due to low water potential.

\section{CONCLUSIONS}

Crop production in any location in the world cannot be carry out meaningfully without enough water supply to the crops, but unfortunately, due to climate changes and its impact on the environment, most crops are grown in many parts of the world without enough water supply at some parts of the crops developmental stages.
It is against this background that is research was carried out to look at the impact or effects of water deficit on the vegetative and reproductive yield process and yield components of maize plant. From this research, the following observations were made:

1) Water deficit at jointing stage, plant height, length of internodes 4-7. elongated section were significantly reduced, and the first 8 to 11 leaf length and width, leaf area and photosynthetic rate decreased significantly. While the impact to Zhongdan5485 was not significant.

2) In jointing stage, water deficit decrease maize production significantly. Furthermore, in soil water content of $40 \%$ to $50 \%$, ear length, diameter, rows per ear and grain number decreased significantly.

3) Water deficit at big flare period had no significant effect on plant height and stem diameter, but the length of the elongated section between 14 and 15 decreased, but in Zhongdan5485 the first single leaf length and width was not impacted while Xundan20 significantly reduced width and leaf area per plant 13 to 15 leaves; soil water content of $45 \%$ to $55 \%$ of the process to make Xundan20 and in Zhongdan5485 alone the photosynthetic rate of ear leaf decreased significantly, while SPAD value, Fv/Fm did not change significantly.

It is necessary to know such effects of water deficit at different stages of crop growth in order to develop crop management strategies to minimize the risk in maize production. Therefore, this research was conducted to determine the effects of water deficit at vegetative and reproductive stages on growth and productivity of maize and therefore conscious efforts must be made at all levels of the maize growth stages throughout their developmental process to ensure maximum output. The importance of these results in this experiment will enable plant producers to focus and have a fair idea as to which stage of the maize plant's development that much attention must be given to in terms of water supply.

\section{REFERENCES}

Acevedo, E.-Hasio, T. C.-Henderson, D. W. (1971): Immediate and subsequent growth response of maize leaves to changes in water status. Plant Physiology. 48: 631-636.

Aparicio-Tejo, P. M.-Boyer, J. S. (1983): Significance of accelerated leaf senescence at low water potential for water loss and grain yield in maize. Crop Sci. 23: 1198-1201.

Araus, J. I.-Slafer, G. A.-Reynolds, M. P. (2002): Plant breeding and drought in C3 cereals, what should we breed for? Ann. Bot. 89: 925-940.

Bergamaschi, H.-Dalmago, A. G.-Bergonci, I. J. (2004): Water supply in the critical period of maize and the grain production. J. Pesquisa Agropecuaria Brasileira. 39: 831-839.

Critchley, W.-Klaus, S. (1999): A manual for the design and construction of Water Harvesting Schemes for Plant Production.

Doebley, J. F. (1994): Morphology, molecules, and maize. [In: Johannessen, S.-Hastorf, C. A. (eds.) Corn and culture in the prehistoric New World. Westview Press. Boulder. Colo. 101-112.

Duysen, M. E.-Freman,T. P. (1975): Partial restoration of the high rate of plastid pigment development and the ultra-culture of platis in detached water stressed what leaves. Plant Physiology. 55: 768-773.
Earl, H. J.-Tollenaar, M. (1998): Relationship between thylakoid electron transport and photosynthetic $\mathrm{CO}_{2}$ uptake in leaves of three maize (Zea mays L.) hybrids. Photosynth. Res. 58: 245-257.

El-Neomani, A. A.-El Halim, A. K. A.-El Zeynu, H. A.-Abd El Halim, A. K. (1990): Response of maize (Zea mays L.) to irrigation intervals under different levels of nitrogen fertilization. Egypt. J. Agron. 15: 147-158.

FAO (2008): Climate-related Transboundary Pests and Diseases Including Relevant Aquatic Species. Expert meeting. February 2008.

Hallauer, A. R.-Miranda, J. B. (1988): Quantitative Genetics in Maize Breeding. 2nd edition. Iowa State Univ. Press. Ames. Iowa.

Heiniger, R. W. (2001): The impact of early drought on corn yield. Raleigh. NC: North Carolina State University. http://www.ces. ncsu.edu/plymouth/cropsci/docs/early_drought_impact_on_corn. html.

IPCC (2007): Intergovernmental Panel on Climate Change - Climate Change 2007: Impacts, Adaptation and Vulnerability. [In: Parry, M. L. et al. (eds.) Contribution of Working Group II to Fourth Assessment Report of the Intergovernmental Panel on Climate Change.]Cambridge University Press. Cambridge. UK. 
Jamieson, P. D.-Martin, R. J.-Francis, G. S. (1995): Drought influence on grain yield of barley, wheat and maize. NZ. J. Crop and Hort. Sci. 23: 55-66.

Kisman, A. (2003): Effects of drought stress on growth and yield of soybean. Sci. Phil. Term paper. Borgor Agric. Univ. (Institute Pertanian Borgor).

Kramer, P. J. (1980): Drought stress and the origin of adaptation. [In: Turner, N. C.-Kramer, P. J. (eds.) Adaptation of Plants to Water and High Temperature Stress. John Wiley and Sons. New York.

Leipner, J.-Fracheboud, Y.-Stamp, P. (1999): Effect of growing season on the photosynthetic apparatus and leaf antioxidative defenses in two maize genotypes of different chilling tolerance. Environ. Exp. Bot. 42: 129-139.

Lobell, D. B.-Bänziger, M.-Magorokosho, C.-Vivek, B. (2011): Nonlinear heat effects on African maize as evidenced by historical yield trials. Nature Climate Change. 1: 42-45.

Nesmith, D. S.-Ritchie, J. T. (1992): Short and long term response of corn to pre-anthesis soil water deficit. Agron. J. 84: 107-113.
Osborne, S. L.-Schepers, D. D.-Francis, J. S. (2002): Use of spectral radiance to estimate in season biomass and grain yield in nitrogen and water stress on corn. Crop Science. 42: 165-171.

Parry, M. L.-Canziani, O.-Palutikof, J. P. (2007): Climate Change 2007: Impacts, adaptation and vulnerability. Cambridge University Press. Cambridge. UK.

Rosegrant, M. W.-Ringler, C.-Gerpacio, R. (1999): Water and Land Resources and Global Supply. [In: Peters, G. H.-von Braun, J. (eds.) Food Security, Diversification and Resource Management: Refocusing the Role of Agriculture.] Proceedings of the $23^{\text {rd }}$ International Conference of Agricultural Economics held at Sacramento, California 10-16 August 1997. England: University of Oxford.

Sarwar, A. K. M. G.-Ali, M. A. (1999): Effect of water stresses on the growth features of different maize (Zea mays L.) cultivars. Pakistan J. Botany. 31. 2: 455-654.

Stickler, F.-Wearden, C. S.-Pauli, A. W. (1961): Leaf area determination in grain sorghum. Agron. J. 53: 18. 